\title{
College English Teaching Reform Mode Study on Internet + Vision
}

\author{
Xia Wang ${ }^{1}$ \\ ${ }^{1}$ Foreign Language Teaching and Research Department, JiLin University of Finance and Economics, \\ China
}

Keywords: The Internet, Vision, multimedia technology, Multimodal synergy, College English teaching reform

\begin{abstract}
With the continuous development of new media age, pay more attention to in the English reading teaching mode to the cultivation of the ability to read more. Multimodal collaborative teaching model is gradually recognized and accepted by people, and the long-term teaching practice proves that the mode of collaborative teaching method is effective, is not only beneficial to the teaching content of effective communication, helps the student to the knowledge understanding and application, to further improve the quality of teaching has the irreplaceable effect. College English teaching is an important part of higher education, for students to further expand international field of vision, know the latest information in the professional, reading literature, and communicate with foreigners and have great significance. Based on this background, in this article the author will study the multiple mode based on multimedia college English teaching.
\end{abstract}

\section{Introduction}

The concept of multimodal conversational ability in 1994 by the American, British and Australian scientists put forward for the first time. In today's global economy rapid development, in order to adapt to the trend of the development of science and technology brought about by the diversity of language and culture and the multiplicity of the channels of communication, they discussed in this situation, the new development of English teaching, formally put forward the concept of multimodal literacy ability. The development of new media era which changes the traditional way of read releasing huge, some language symbols, such as: space, such as images, sounds, the status of the constantly highlighted, combined with traditional language symbols, and plays an important role in the social life together, profoundly influenced the English teaching concept, method and content [1]. Modal read more in order to develop students ability, English teachers are in the reading teaching adopt diversified teaching methods, combined with modern information technology on auxiliary teaching, trains the student to multimodal literacy ability, can make the students' creativity and aesthetic feeling.

For example in learning to read a sentence, the teacher can deserve to go up next to the sentences related pictures, or use the recording, animation in the form of the sentence mean better performance, lets the student can deeply realize the actual situation of English sentences. By cultivating students' multimodal literacy ability, make the English reading teaching produces good effect. From the point of view of students, cultivate students multimodal conversational ability can promote the development of English teaching [2]. Specifically, multimodal conversational ability refers to rely on English reading access to a variety of modal and the media, and the ability, causes the student to produce new information on the basis of the multimodal literacy is a multi-level ability.

College education level development imbalance, the development of education resources is due to the condition of uneven obviously in a variety of teaching resource in our country, the gap of education resources between different colleges and universities may be very different, students' cognitive degree in college English learning is different also [1]. Education teaching level of the development of the imbalance makes some students are in the process of learning English in some difficulties, and the emergence of the Internet horizon can well make up the balanced education resources situation, realized the popularization of education of college English learning. Also break the monopoly of some famous universities for teaching resources. 


\section{Multimedia vision for the reconstruction of teaching mode of college English}

Horizon for the teaching mode of higher education influences the Internet is huge, it is accompanied by a happy science and technology of a kind of new teaching mode, and also a new achievements in education technology [2]. Internet horizon has important influence on the teaching in colleges and universities in our country. We can't be stuck in the past, should be gradual steady Internet horizon of English teaching mode.

The existing English teaching pattern of Internet horizon is gradually plays a very important influence.

The traditional teaching mode can't satisfy the need of students. The current college English teaching mode, not to meet the students' individualized learning needs. Various colleges and universities under the influence of different operating conditions, implement the system of English learning of the credit system, a comprehensive course of study and audio-visual classroom learning. But due to the limitation of the actual situation, some colleges and universities can't complete the basic teaching of college English course [1]. At the same time this kind of teaching mode can't meet the personalized needs of contemporary college students in English language learning. Many students in the learning process of traditional tired of emotions, such as forced to study the patterns of change. Internet horizon of learning can satisfy this requirement.

In multimodal discourse analysis theory, there are two factors are indispensable, is a medium, the second is the modal. The so-called media, is the carrier of information communication between people and people, like sound propagation need medium, air is a medium of more common, extreme thin air content in the space, so even if face to face, also can't hear each other, only by means of radio. So in multimodal discourse analysis theory, the two basic elements is a very close connection between [2]. On the one hand, the development of multimedia technology has given rise to new forms of discourse, the original people face to face talk and communication, but as a result of the development of mass media, television and other new technology, an information can be more widely spread more effectively, more and more people can get the information at the same time; Multimodal together, on the other hand, also need with the aid of multimedia tools, such as the sound of record and the accumulation of corpus and update, etc. In short, many modal coordinate theories of media and modal between closely related, influence each other, and promote each other.

Multimodal cooperative teaching method in college English listening teaching is based on the theory of multimedia together, as much as possible in the classroom teaching advices from different senses. With the development of social economy and the continuous improvement of the higher education teaching hardware facilities, the multimedia technology on the basis of multimodal synergy of college English listening teaching has been more and more widely in the region, and has achieved very good [3]. This is because the traditional listening teaching mode is a kind of pure rely on auditory for listening learning mode, the single input channel was not enough stimulation to the brain language area, so the teaching effect and students accept the effect is not very good, and multimodal collaborative mode, add video, in the process of listening comprehension and in true began to listen to the tape with a background introduction, finally combined with oral retelling the content, it will simply become a listen to the conversation to answer the question in listening, speaking, reading and sometimes there will be written to foster and improve the comprehensive ability, from the perspective of modal input, this is the input of auditory input into both involved in vision, and hearing, in accordance with the process of the a comprehensive study of language output.

\section{Multimodal cooperative teaching method in college English teaching}

Many modal coordinate teaching factors. Leader and organizer of college English teaching is a teacher of English, even if the present reform of higher education are students in the classroom is not just passively accept knowledge, but gradually become the main body of the classroom, teachers as the organizer and leader role has not changed. In the actual college English teaching, teachers can use multimedia technology with the support of multimodal collaborative teaching mode. First of all, the teacher may, by way of using graphics, animation, and other comprehensive arouses student's senses, 
and to assist course effectively. In addition, there are conditions of colleges and universities, can consider to add touch means to improve the students' senses, thus deepening the understanding of the content of the material, ability can be improved [3]. In addition, the teacher is in itself the participants in the classroom, modal and auditory and visual modal source of effective and important way, such as multimedia technology, the teacher's instructions, gestures, body language, etc., can help students' modal together to learn more English knowledge, ability can be improved.

The design of the multimedia content is also very important, the teacher should complete the contents of the classroom before the class preparation work, clear the student ability weak link and the reasons for the weak link, and then a targeted to give guidance and help.

Student's multimodal collaborative learning factors. Modern education increasingly pay more attention to the subject status of students in the classroom, the students are the classroom knowledge objects, teachers should suit the students' actual level of job of teaching, but students should also actively transform basic education stage English learning methods, increase awareness of active learning. In basic education stage, because of the large entrance pressure and other reasons, main using acoustic modal English classroom, and sometimes the only, the students improve ability, to master skills, improve English comprehensive quality is very bad, so this is just a product of the exam-oriented education. In this kind of education mode, the students tend to be seriously enough, or simply think is just a test project, to be able to get scores is fine, so understanding of ability is not enough, and easy to produce tired of emotions and refuse [4]. Little imagine, college English education is no longer just concentrating on grades but improve the comprehensive ability, students if not timely shift in thinking, will affect the improvement of college English, is not conducive to further improve of their comprehensive qualities and to achieve the goal of all-round development.

Under the multimedia technology of multimodal synergy of college English teaching in class, students will be able to follow the teachers' teaching task arrangement, the auditory, visual learning, experiential or four aspects practical learning, perception of different sources of language activities, get "immersion" learning. And, in the process of learning, students will also be able to get from the outside of multimedia means of communication and guidance, such as the explanation of teachers and students of mutual information between the process, so compared with the original "cramming" teaching classroom, multiple mode based on multimedia technology under the synergy of college English teaching classroom teaching means more rich, students can also greatly increase the perceived information sources, from only the teachers' oral, into today joined the multimedia images, voice, and between the classmate mutual exchange and communication [4]. These methods not only improve the students' classroom participation, but also conducive to further stimulate students' interest in learning of college English courses, to improve their English language ability, and promote their all-round development.

Multimodal collaborative teaching in college English teaching. For college English course, acoustic modal should occupy the main aspects, but are by no means the only, the other three ability can promote the improvement of ability, the improvement of comprehensive ability is also very important. So the multiple modes based on multimedia technology together can't according to the traditional way of teaching college English teaching, emphasis on ability and not only pay attention to the cooperation and coordinated development of other abilities [4]. Therefore, this requires college English teachers should have the ability to different resources and the teaching mode of coordinated ability, optimizing classroom teaching content and mode, improve teaching efficiency, let the students can get maximum capacity in unit time, so as to achieve multiple mode based on multimedia technology synergy of college English teaching method is designed. Then the author multiple mode based on multimedia technology collaborative goal of college English teaching mode, specific measures, for readers reference.

For some does not adapt to the new teaching method of students, teachers should give more attention, help them as soon as possible from the original teaching methods to adapt to the new teaching mode, stimulate their potential, improve the learning enthusiasm and initiative [4]. Teachers can appropriate homework after class, let the students to learn the knowledge in the classroom, reflection and has yet to grasp the knowledge, and the teachers should follow up study some spare 
capacity, appropriate to give guidance, make their potential into full play, to further improve the effect of college English teaching, improve the comprehensive quality of students.

Acoustic modal of the dominant position. Auditory mode in college English teaching should also occupy the main aspects, because the course is designed to improve the ability of that power, so the acoustic modal is the main body, other modal on the dog, not point. But other modal should revolve around acoustic modal this topic. Teachers can consider to cooperate with pictures, video and other means, improve the students' information and rapid response to the complex information integration ability, able to get what they want in a short time as a result, summing up the meaning of information and the main idea [5]. But teachers should note that in college English classroom, should time, focusing on the acoustic modal cannot a presumptuous guest usurps the host's role. And in class the teacher should provide some video or audio data to the student, let them to have a brief understanding of the course content, which is beneficial to improve the classroom efficiency, improve the students' learning interest, also is helpful for students to deepen the understanding of the teaching content and grasp. In the classroom, the teacher should focus on students; different levels of learning ability as far as possible let each student can improve ability under multimodal collaborative teaching methods.

The addition of visual mode. In the multiple mode based on multimedia technology in collaborative college English teaching, visual modality is also important. Scientists have pointed out that in the information received by people, there is $80 \%$ through visual sources, so even in modal occupied the main position of the college English classroom, should also join the appropriate visual mode, it will play a very important supplement to the modal function and effect, is also a useful complement to classroom teaching [5]. Modern education students in accordance with the ability to improve the learning style of concrete can be divided into visual, feelings and three types of auditory, visual mode is to enable students to join the most intuitive understanding of the material content, key way better clear material, so no matter which kind of students, to improve their ability, improve the learning effect.

The sense of touch mode. The multiple modes based on multimedia technology synergy in terms of college English teaching, in addition to acoustic modal dominance, touch mode is also very important. In college English class, the so-called sense of touch mode is refers to the teachers and students, between students and students and the teachers and students and teaching hardware facilities directly contact. Relatively, due to the school hardware facilities is relatively fixed, so touch mode between teachers and students much more mobile and flexible [6]. College English teaching is also sometimes come into contact with the sense of touch mode, according to the material, for example, students often have to discuss, to use the hardware facilities, and then there will be the use of touch mode. Modal usage is not much, but the sense of touch but it as in a form of objective existence in the college English teaching, to improve the classroom task completion and flexibility, diversity, still has an irreplaceable role. Teachers based on multimedia technology in the design of multiple cooperating mode of college English teaching classroom content, need not deliberately to join touch the content of the modal, want to use it as acoustic modal and visual modal of a kind of beneficial complement, coordination, and adhere to the student to raise the level of the most fundamental tasks.

Correlation between modal. In college English classroom teaching, combining with correlation between modal is also need to consider. Multimodal teaching requires teachers to organize well the relationship between the different modes, adjusting the proportion of its existence form and quantity level, between the different modal can achieve the optimal configuration, to the coordinated development of each other [6]. From the guiding ideology and principle, the teacher should adhere to the auditory mode as the main body, supplemented by visual mode, when necessary to join the sense of touch and other forms of modal. Teachers in the process of preparation should be well balance the ratio between the visual and audio materials, at the same time to focus on the relationship between them, not red herrings, license hearing materials to use visual materials. And teachers should also consider the difficulty of the selection of material, let the students can accept, so that they can't think too simple, because these two approaches are likely to be adverse impact on their learning the enthusiasm. 


\section{Summary}

In the era of new media English teaching with new features and tasks, teachers can adopt effective in English reading instruction and guidance, critical reading and so on auxiliary method, promote students' critical thinking abilities and the formation of cross-cultural awareness. Multimodal teaching of English reading teaching emphasizes on the animation, pictures, words and sound symbols such as the comprehensive use, set up a reading, strengthen students' perception and understanding of the information, storage, coding, language output, through the use of automation has trained the students' ability to read.

\section{References}

[1] Sh.Y. Wang and X.W. Miao, The theory and method of English teaching, Foreign language audiovisual education, 2013, vol.8, pp.1-5.

[2] W.H. Qin, More modal and college students read capability study, Foreign language audiovisual education, 2009, vol.4, pp.28-32.

[3] D.L. Zhang, Comprehensive theoretical framework to explore multimodal discourse analysis, Journal of foreign languages in China, 2009 vol.1, pp.24-30.

[4] Zh.Y. Sheng, Multimodal discourse analysis of the theoretical basis and research methods, Journal of foreign languages, 2007, vol.5, pp.82-86.

[5], J.Sh. Hu, Horizon of our country, the impact of the college English course and reconstructing, Foreign language audio-visual teaching, 2014, vol.3, pp.76-80.

[6] J.H. Guo and H.T. Li, Many modal of each new mode of college English teaching, Journal of Hunan university of technology (social science edition), 2011, vol.4, pp.42-46. 